\title{
Victims of crime with intellectual disabilities and Ireland's adversarial trial: some ontological, procedural and attitudinal concerns
}

\author{
Alan Cusack
}

School of Law, University of Limerick

\begin{abstract}
That the process of delivering evidence orally in court can prove stressful and intimidating is a point well established within mainstream victimological discourse. ${ }^{1}$ However, what is insufficiently acknowledged, particularly within the Irish academy's literature on this topic, is the extent to which this sense of distress is heightened for victims of crime with an intellectual disability. In seeking to address this research lacuna, this paper will consider the degree to which the procedural norms of Ireland's adversarial trial system, and the epistemic values which underpin those norms, pose certain exaggerated barriers to the realisation of justice for members of this vulnerable victim constituency. Owing to their limited cognitive and linguistic development, these victims face significant biomedical or ontological difficulties in responding to experiences of victimbood. Crucially, however, these ontological difficulties are compounded both procedurally and attitudinally by an adversarial system of trial which is predicated upon a 'contest morphology' and controlled by a legal community that is overwhelmingly preoccupied with mainstream accounts of victimbood.
\end{abstract}

Keywords: criminal process; victimology; adversarial procedure; crime victims; intellectual disability; evidence

\section{Introduction}

$\mathrm{I}^{\mathrm{s}}$ reland's adversarial trial, like many of its counterparts across the common law world, has traditionally accommodated a rigorous, interrogative programme for testing proofs in court. The oral nature of proceedings, the combative sensibilities which underpin them, the emphasis on witness demeanour, the insistence upon unmediated responses, the freedom of advocates to engage in robust cross-examination and the forensic passivity of the trial judge and jury are all regarded as essential evidential safeguards in securing a fair adversarial trial for the criminal accused. ${ }^{2}$ For victims of crime, however, these evidential safeguards

* Lecturer in Law, School of Law Limerick. The author would like to thank the journal reviewers for their helpful comments on an earlier draft of this article and wishes to acknowledge the funding provided by the Irish Research Council Postgraduate (Government of Ireland) Scholarship, without which this research would not have been possible. The views expressed, as well as any errors contained within, remain the sole responsibility of the author.

1 See, for example, S Lees, Carnal Knowledge: Rape on Trial (Hamish Hamilton 1996); S Walklate, Imagining the Victim of Crime (Open University Press 2007); G Matoesian, Reproducing Rape: Domination through Talk in the Courtroom (University of Chicago Press 1993).

2 See, dicta of Gannon J in State (Healy) v Donoghue [1976] IR 325, 335-6. 
often contribute to an intimidating, frequently hostile, courtroom environment. As Doak explains, ' $[\mathrm{t}]$ he adversarial trial process, as its name would suggest, is not designed to protect witnesses, and nor is it a place where the weak and vulnerable can feel relaxed and at ease'. ${ }^{3}$ Indeed, if, as Ellison contends, the process of delivering evidence orally in court is 'a difficult and stressful ordeal for many witnesses', the experience is arguably even more so for vulnerable witnesses such as those, for instance, who approach the steps of the courthouse with an intellectual disability. 4

Owing to limitations in cognitive functioning and linguistic fluency, victims of crime with intellectual disabilities often face severe difficulties in responding to incidents of victimisation. While it is true, as many commentators have pointed out, that all crime victims can expect to experience some degree of marginalisation within the adversarial trial given its bifurcated (i.e. state-versus-accused) structure and its public character, the exclusion felt by members of this vulnerable victim constituency is particularly acute. ${ }^{5}$ It is this heightened sense of procedural exclusion which forms the basis of this article. By focusing on the ontological, procedural and attitudinal factors which uniquely contribute to the exclusion of victims of crime with intellectual disabilities at trial, it is hoped that this brief contribution will go some way to exposing the mainstream assumptions which underpin Ireland's adversarial model of justice. In so doing, the article is intended to act as an emboldening reference point for Irish policymakers, encouraging them to reconsider the types of evidential safeguards that are truly required to secure a fair trial for a criminal accused in light of the experience of victims of crime with intellectual disabilities.

\section{Ontological barriers to best evidence}

An important disclaimer, which must be issued at the outset of any exploration of the ontological or biomedical dimensions of intellectual disability, is that intellectually disabled individuals do not form a homogeneous group. The types of impairment which exist, the level of their severity and the degree to which they inhibit normal social functioning can vary greatly between people falling within this classification. ${ }^{6}$ As such, it is impossible to identify authoritatively the full spectrum of ontological or biomedical factors which impact upon the testimonial performance of this heterogeneous group. However, given their shared cognitive disposition and adaptive behavioural characteristics, certain global comments can be made in relation to the capacity of persons with an intellectual disability to act as witnesses within Ireland's adversarial trial process. ${ }^{7}$

As a preliminary point, many people with intellectual disabilities have been found to have broad deficits in memory encoding, storage and retrieval. ${ }^{8}$ Consequently, such

3 J Doak, 'Confrontation in the Courtroom: Shielding Vulnerable Witnesses from the Adversarial Showdown' (2000) 15(3) Journal of Civil Liberties 296.

4 L Ellison, 'The Protection of Vulnerable Witnesses in Court: An Anglo-Dutch Comparison' (1999) 3 International Journal of Evidence and Proof 29.

5 J Doak, 'Victims' Rights In Criminal Trials: Prospects For Participation' (2005) 32 Journal of Law and Society 294, 295; A Goldstein, 'Defining the Role of the Victims in Criminal Prosecution' (1982) 52 Mississippi Law Journal 515.

6 M R Kebbell and C Hatton, 'People with Mental Retardation as Witnesses in Court: A Review' (1999) 37(3) Mental Retardation 179; G H Gudjonsson and L Henry, 'Child and Adult Witnesses with Intellectual Disability: The Importance of Suggestibility’ (2003) 8 Legal and Criminological Psychology 241.

7 M R Kebbell, C Hatton, S D Johnson and C M E O'Kelly, 'People with Learning Disabilities as Witnesses in Court: What Questions Should Lawyers Ask?' (2001) 29 British Journal of Learning Disabilities 98.

$8 \mathrm{M}$ Ternes and J C Yuille, 'Eyewitness Memory and Eyewitness Identification Performance in Adults with Intellectual Disabilities' (2008) 21 Journal of Applied Research in Intellectual Disabilities 509; M R Kebbell, C Hatton and S D Johnson, 'Witnesses with Intellectual Disabilities in Court: What Questions are Asked and what Influence do they have?' (2004) 9 Legal and Criminological Psychology 23. 
witnesses have been found to encounter significant difficulty in providing spontaneous accounts of eyewitness events. ${ }^{9}$ Moreover, emerging evidence from the field of cognitive psychology suggests that a large proportion of these witnesses are susceptible to a range of additional debilitating psychological vulnerabilities which can significantly impair their capacity to deliver accurate courtroom testimony. Numerous studies, for example, have found that individuals with intellectual disabilities are more suggestible, more acquiescent, more likely to confabulate and more likely to engage in nay-saying than their counterparts within the general population. ${ }^{10}$

There is also evidence to suggest that such witnesses are more likely to obfuscate generic details about an alleged incident, such as names, times and dates, ${ }^{11}$ that they will entertain a final option bias in response to closed-multiple choice questions, ${ }^{12}$ that their knowledge of the legal process is poor, and that they struggle routinely to comprehend legal terminology. ${ }^{13}$ Additionally, each of these psychological vulnerabilities can be significantly exacerbated by a range of environmental factors associated with the setting in which a witness's narrative is elicited. It is particularly apparent from the research that exists in this area that a witness's responses will be biased by both the status of the interviewing actor and the formality of the venue in which the exchange is taking place. ${ }^{14}$

However, while these insights from the field of cognitive psychology raise serious questions about the reliability of testimony elicited from witnesses with an intellectual disability, they should not be interpreted as giving cause to automatically discredit a witness simply by virtue of his or her intellectual impairment. There is, as Gudjonsson points out, no empirical basis for treating as unreliable the evidence of a witness simply because its author presents it with a number of psychological vulnerabilities: 'Persons with moderate learning disability may well be able to give reliable evidence pertaining to basic facts, even when they are generally highly suggestible and prone to confabulation.' 15 The central controlling factor, it would seem, is the manner in which he or she is questioned about an alleged incident.

Broadly speaking, the dominant research in this field would appear to indicate that the more specific the question asked, the less factually accurate the ensuing response. ${ }^{16}$ Thus, whereas open questions (e.g. What happened?) tend to yield a highly accurate, if somewhat factually incomplete, response; closed questions have been found to elicit a

9 B Tully and D Cahill, Police Interviewing of the Mentally Handicapped (Police Foundation 1984); N B Perlman, K I Ericson, V M Esses and B J Isaacs, 'The Developmentally Handicapped Witness: Competency as a Function of Question Format' (1994) 18 Law and Human Behaviour 171.

10 I C H Clare and G H Gudjonsson, 'Interrogative Suggestibility, Confabulation and Acquiescence in People with Mild Learning Disabilities (Mental Handicap): Implications for Liability in Police Interrogations' (1993) 32 British Journal of Clinical Psychology 295; Gudjonsson and Henry (n 6).

11 Kebbell, Hatton, Johnson and O'Kelly (n 7); N Beail, 'Interrogative Suggestibility, Memory and Intellectual Disability' (2002) 15 Journal of Applied Research in Intellectual Disabilities 129.

12 L W Heal and C K Sigelman, 'Response Biases in Interviews of Individuals with Limited Mental Ability' (1995) 39(4) Journal of Intellectual Disability Research 331.

13 K I Ericson and N B Perlman, 'Knowledge of Legal Terminology and Court Proceedings in Adults with Developmental Disabilities' (2001) 25(5) Law and Human Behaviour 529.

14 G H Gudjonsson, G H Murphy and I C H Clare, 'Assessing the Capacity of People with Intellectual Disabilities to Be Witnesses in Court' (2000) 30 Psychological Medicine 307; G H Gudjonsson and J Gunn, 'The Competence and Reliability of a Witness in a Criminal Court: A Case Report' (1982) 141 British Journal of Psychiatry 624.

15 G H Gudjonsson, The Psychology of Interrogations and Confessions (Wiley 2003) 334.

16 Kebbell and Hatton (n 6); H Dent, 'An Experimental Study of the Effectiveness of Different Techniques of Interviewing Mentally Handicapped Child Witnesses’ (1986) 25 British Journal of Clinical Psychology 13. 
more detailed response which is less factually precise. ${ }^{17}$ This phenomenon was recognised by Perlman et al who arrived at the conclusion following their empirical research in this area: 'In contrast to the more open-ended recall formats, it appears that less accurate reports are obtained with more focused recall questions for both groups, but particularly for the developmentally handicapped group. ${ }^{18}$ Given, then, that the adoption by lawyers of an appropriate questioning strategy in court can significantly mitigate the response biases of witnesses with intellectual disabilities, it is wrong to assume that the cognitive limitations of members of this victim constituency present ontological challenges which are insurmountable within the criminal process. However, for best evidence to prevail, the design of the trial is key.

\section{Procedural barriers to best evidence}

Owing to the legacy of colonialism, the procedural architecture of Ireland's trial has long been designed in the style and form of the adversarial tradition; that is to say, a tradition which celebrates justice secured through the confrontational, oral interaction of partisan parties who, in accordance with strictly delineated rules, engage in a gladiatorial contest before a neutral judge and jury. From an epistemological perspective, however, the procedural inclusivity and probative integrity of this confrontational tradition is highly questionable. Indeed, by insisting upon the delivery of direct oral evidence, the adversarial trial prematurely assumes that all honest witnesses are equally capable of constructing story narratives, of relaying those narratives in a credible manner, of withstanding the rigours of cross-examination and of calmly confronting an assailant in court. ${ }^{19}$ In short, it fundamentally discounts the fact that witnesses are not uniformly articulate, confident and cognitively developed. As a consequence, Ireland's adversarial trial invites an inherent bias against those who lack shared cognitive routines for presenting evidence in storycoded forms'. ${ }^{20}$ This sense of procedural bias, it is submitted, is most acutely apparent at two distinct phases of the Irish trial, namely (1) in satisfying the competency standard to testify; and (2) in subsequently delivering viva voce evidence in open court.

\subsection{COMPETENCY STANDARD AS A BARRIER TO INCLUSION}

While the admission of unsworn testimony from persons with a 'mental handicap' under the Criminal Evidence Act 1992 represented a welcome departure from the exclusionary approach of the common law, ${ }^{21}$ the modified competency test ushered in by this Act has not been a panacea for all of the competency difficulties which witnesses with intellectual disabilities face in Ireland. As a preliminary point, unsworn evidence is hardly comparable to evidence given under oath in terms of its persuasive force. Inferences of unreliability, as Birch reminds us, are almost inescapable for jurors tasked with weighing up such testimony:

Competence does not ... imply credibility and an adult witness who has been found fit 'only' to give unsworn evidence of abuse allegedly occurring in private is likely to be off to a bit of a shaky start, especially where there is no corroboration. $^{22}$

17 Heal and Sigelman (n 12).

18 Perlman et al (n 9) 181.

19 See J McEwan, Evidence and the Adversarial Process: The Modern Law (Hart 1998) 15.

20 W Bennett and M Feldman, Reconstructing Reality in the Courtroom (Sweet \& Maxwell 1981) 171.

21 Prior to the enactment of s 27 Criminal Evidence Act 1992, there was no mechanism under Irish law by which adults, including those with an intellectual disability, could give unsworn testimony in court. See Mapp v Gilhooley [1991] 2 IR 253 (SC), 262.

22 D Birch, 'A Better Deal for Vulnerable Witnesses?' (2000) Criminal Law Review 223, 231. 
The shakiness of this start, moreover, is all but assured by the procedural delay which invariably accompanies competency assessments in Irish criminal proceedings. Studies have shown that, for victims of crime with intellectual disabilities, recall accuracy is inversely related to the length of time which elapses between the criminal incident and the date upon which it is relayed in court. ${ }^{23}$ Accordingly, a witness's capacity to give an intelligible account may be significantly compromised by the procedural delay which is now an engrained feature of modern Irish criminal litigation. ${ }^{24}$

Additionally, awkward questions need to be addressed concerning the suitability of trial judges to act as arbiters of witness competency in the first place. Although expert medical opinion evidence may be adduced to assist the court in assessing the competency of a witness, the final determination of this issue rests with the trial judge. ${ }^{25}$ In this regard, Edwards et al's recent discovery that members of Ireland's judiciary execute competency determinations on an ad hoc basis without reference to strict psychological or medical criteria is a cause for some concern. Citing, for instance, the usefulness of school reports as a source of evidence for competency determinations, one judicial member interviewed as part of the study commented as follows:

These things can be helpful in kind of fleshing out, giving a clearer idea of how far the person had capacity to go in terms of education, just general training, looking after themselves, you know, awareness of the outside world etc. ${ }^{26}$

It is submitted that the absolute discretion which is currently afforded to the Irish judiciary in determining issues of competency in accordance with their own individualised notions based on arbitrary questioning formats is entirely inappropriate and provides an unruly template for assuring equal access to justice for witnesses with an intellectual disability. The Laura Kelly case strikingly illustrates this point. The complainant in this case was a young woman with Down's Syndrome who was allegedly sexually assaulted at a 21 st birthday party. At the trial, however, the complainant, who was described by the Central Criminal Court as having 'a mental age of four', was deemed incompetent to testify and the case was dismissed. Following this determination, the complainant's mother expressed her deep sense of dissatisfaction with the competency standard applied by the court:

[Laura] was brought into this room in the Central Criminal Court and asked questions about numbers and colours and days of the week which had no relevance in Laura's mind. She knew that she had to go into the courtroom and tell a story so the bad man would be taken away . . . It was ridiculous. There is no-one trained in Ireland to deal with someone similar to Laura, from the Gardaí up to the top judge in Ireland and the barristers and solicitors. 27

This statement encapsulates the flawed conception of competence which Irish courts continue to entertain in criminal proceedings. Indeed if, as psychological studies have shown, ${ }^{28}$ persons with intellectual disabilities have an increased recollective capacity for salient life experiences, then the trial judge's exclusive focus in the Laura Kelly case on

23 According to Heal and Sigelman the capacity of persons with intellectual disabilities to give a consistent account over even a short period (one week) was 'substandard'. See Heal and Sigelman (n 12) 331.

24 National Crime Council, An Examination of Time Intervals in the Investigation and Prosecution of Murder and Rape Cases in Ireland from 2002-2004 (Government Publications Office 2006).

25 People $(A G) v$ Kehoe [1951] IR 70, 71.

26 C Edwards, G Harold and S Kilcommins, Access to Justice for People with Disabilities as Victims of Crime in Ireland (University College Cork 2012) 111.

27 J McEnroe, 'Family Want “Archaic_LLaw Overhauled’ Irish Examiner (Cork, 30 March 2010).

28 Gudjonsson and Gunn (n 14). 
impersonal, generic information was psychologically unsound. Worse still, his approach was rooted in a disabling, overly pathological understanding of disability. Instead of adopting a functional approach to capacity as mandated by s 3 of the Assisted DecisionMaking (Capacity) Act 2015, and instead of considering whether the complainant had the capacity to impart information relevant to the matter at hand (i.e. give an intelligible account of the alleged crime), the test employed by the trial judge focused entirely on irrelevant details. Not only is such an approach to witness competency discredited within mainstream evidential scholarship, but it has also been discredited in wider areas of mental capacity law. ${ }^{29}$

\subsection{GIVING EVIDENCE AS A BARRIER TO INCLUSION}

As Murphy $\mathrm{J}$ in Phonographic Performance Ltd $v$ Cody was at pains to point out, the Irish adversarial trial is founded on a deep-seated belief that oral evidence is best: "The examination of witnesses viva voce and in open court is of central importance in our system of justice and . . . it is a rule not to be departed from lightly. 30 This centrality of oral evidence within Ireland's adversarial trial is attributable, in the main, to its perceived evidential richness in terms of providing the jury, not only with a sworn narrative of events, but also with a valuable opportunity to judge the authenticity of this sworn narrative in light of a witness's demeanour in court. ${ }^{31}$

Consistency of account and credibility of recount are therefore crucial to achieving testimonial success within the adversarial trial. Any factual inaccuracy in a witness's version of events, or any behavioural anxiety which he or she may exhibit in the witness stand, can cast fatal doubt on the perceived reliability of the resulting testimony. Moreover, the authenticity of a witness's account is said to assured by the adversarial trial's subscription to a series of rigorous evidential safeguards. ${ }^{32}$ It is axiomatic of adversarial trial justice, for instance, that oral evidence should be delivered upon oath, that its veracity should be confirmed through a process of rigorous cross-examination, that the tribunal of fact should have an opportunity to judge its reliability by observing the demeanour of the witness in court, and that the exchanges which constitute the trial should take place in a public forum appropriate to the solemnity of the occasion. ${ }^{33}$ However, our subscription to these evidentiary safeguards comes at a price. Not only do these canons ignore the ontological challenges of intellectual impairment, but they also arguably exploit them by cultivating a hostile interrogative environment.

\subsubsection{Evidence under oath and cross-examination as a barrier to inclusion}

In their quest to put their best evidence before Irish jurors, victims of crime with intellectual disabilities must endure a rigorous, often invasive, cross-examination process which can have a devastating impact on the coherency, consistency and credibility of their testimony. ${ }^{34}$ Notwithstanding, however, the heightened risk of narrative bias which

29 Birch (n 22); Edwards et al (n 26); R Byrne, 'Sexual Offences and Capacity to Consent: Key Issues' (2015) 5(1) Irish Journal of Legal Studies 22.

30 [1998] 4 IR 504, 521.

31 O G Wellborn, 'Demeanour' (1991) 76 Cornell Law Review 1104.

32 Ellison (n 4) 34.

33 Significantly, physical confrontation in the sense of a face-to-face exchange is not an essential ingredient of Ireland's adversarial trial. See Donnelly v Ireland [1998] 1 IR 321.

34 A Sanders, J Creaton, S Bird and L Weber, Victims with Learning Disabilities: Negotiating the Criminal Justice System (University of Oxford Centre for Criminological Research 1997) 75. 
accompanies the cross-examination of such witnesses, ${ }^{35}$ empirical research suggests that advocates do not adapt their interrogative strategy when confronted with an intellectually disabled witness in court. ${ }^{36}$ Thus, in much the same way as they seek to control the narrative of mainstream witnesses through a range of techniques, so too do lawyers, in cases involving vulnerable witnesses, invoke 'constraining and coercive questioning strategies which have a particularly negative impact on the testimony of witnesses with [learning disabilities]'. ${ }^{37}$

One particularly insidious technique employed routinely during cross-examination is for counsel to have recourse to advanced terminology and complex syntax in court. In this way, lawyers use language as a tool to manipulate and subordinate comparatively naive and vulnerable language users. ${ }^{38}$ There is a wealth of research attesting to the distortive impact which legal parlance can have on the accuracy of testimony provided by witnesses with intellectual disabilities. A study by Smith, for example, found that 16 per cent of offenders with an intellectual disability did not understand the meaning of the word 'guilty', while a further 22 per cent of respondents did not appear to understand the meaning of the phrase 'not guilty'. ${ }^{39}$ A similar dearth of knowledge has been identified in separate psychological studies by Gudjonsson et al, Smith and Hudson, and Ericsson and Perlman respectively. ${ }^{40}$ Significantly, these studies point to the importance of explaining clearly to intellectually disabled witnesses the basic principles, terminology and procedures involved in the adversarial trial: 'The results of this study suggest that when many legal terms are used in questioning and they're not explained to "developmentally disabled" individuals, answers to questions may be confused or incorrect or both. ${ }^{41}$

Additionally, owing to the heightened sensitivity of these witnesses to aggression - as well as their overt desire to appease authority figures - there is a risk that intellectually disabled witnesses will simply feign understanding in order to bring an interrogation to a close and avoid any undue public embarrassment. ${ }^{42}$ As one respondent in McLeod et al's study remarked: 'You can tell people with learning disabilities anything and they would agree or say they had understood. But you really need to check that they actually understand what's being said. 43 It should also be noted, that these difficulties in comprehension are often further compounded by the design of the adversarial trial which makes it difficult for a witness to articulate a lack of comprehension in a manner which does not detract from his or her credibility.

Another popular tendency amongst cross-examining advocates is to construct their examination of a witness almost entirely around coercive, closed-ended, leading

35 Kebbell et al (n 8) 32.

36 Ibid 32; Kebbell and Hatton (n 6).

37 Kebbell, Hatton, Johnson and O’Kelly (n 7) 98.

38 L Ellison, 'The Mosaic Art?: Cross-Examination and the Vulnerable Witness' (2001) 21(3) Legal Studies 353, 355.

39 S A Smith, "Confusing the Terms "Guilty" and "Not Guilty": Implications for Alleged Offenders with Mental Retardation’ (1993) 73 Psychological Reports 675.

40 G H Gudjonsson, I C H Clare and P Cross, "The Revised PACE "Notice to Detained Persons": How Easy is it to Understand?' (1992) 32 Journal of the Forensic Science Study 289; S A Smith and R L Hudson, 'A Quick Screening Test of Competency to Stand Trial for Defendants with Mental Retardation' (1995) 76 Psychological Reports 91; Ericsson and Perlman (n 12).

41 Ericsson and Perlman (n 13) 542.

42 Ibid 531.

43 R McLeod, C Philpin, A Sweeting, L Joyce and R Evans, Court Experience of Adults with Mental Health Conditions, Learning Disabilities and Limited Mental Capacity Report 3: At Court (Ministry of Justice 2010) 9. 
questions. ${ }^{44}$ Narrative control is key for these actors and their overriding concern is to adopt an interrogative approach which best assures them of eliciting an account that is sympathetic to their hypothesis. ${ }^{45}$ Thus, we find advocacy manuals explicitly counselling the untrained advocate to avoid the type of free recall inquiries which best speak to the cognitive strengths of persons with an intellectual disability: 'Almost anything is responsive to a question that asks how? or why? Those words are to be avoided like the plague in cross-examination. ${ }^{46}$ While coercive questioning may well be celebrated in advocacy scholarship for allowing the wily advocate to construct the 'desired reality' in court, they invite an increased risk of confabulation amongst witnesses with an intellectual disability. ${ }^{47}$ Similarly, suggestive questioning - achieved principally through the use of leading questions - has been shown to cultivate an increased suggestibility effect amongst persons with an intellectual disability. 48

A further final technique employed by counsel during cross-examination is their adoption of an overtly hostile and aggressive interrogative demeanour to intimidate opposing witnesses. As Ellison writes:

Tone of voice, speech rate, emphasis, physical proximity, eye contact, physical gesture and facial expression are all devices which can be used to unsettle or unnerve a witness. In addition, an array of conversational ploys are used to intimidate and thereby undermine [an] opposing witness. ${ }^{49}$

The conversational ploys to which Ellison refers include the use of repeated questions, ${ }^{50}$ asking questions in rapid succession, ${ }^{51}$ raising fallacious objections ${ }^{52}$ and paying inordinate attention to trivial and seemingly obscure details about the alleged criminal event. ${ }^{53}$ These tactics are adopted by cross-examining counsel, not singularly for the purpose of intimidating witnesses into giving a sympathetic account of events, but also for the purpose of casting doubt on the credibility of any opposing truth claims raised in court. ${ }^{54}$

\subsubsection{Emphasis on witness demeanour as a barrier to inclusion}

Within adversarial proceedings it is not simply sufficient for a witness to deliver a factually accurate account in court; they must do so in a behaviourally plausible manner. Any failure to conform with behavioural norms associated with truthful storytelling is

44 Kebbell et al (n 7) 99.

45 According to Levy, the cardinal rule of cross-examination is 'thou shalt control the witness'. See E Levy, Examination of Witnesses in Criminal Cases (Thompson Professional 1991) 203.

46 K Evans, Golden Rules of Advocacy (Blackstone 1993) 108.

47 R Milne, I C H Clare and R Bull, 'Interrogative Suggestibility Among Witnesses with Mild Intellectual Disabilities: The Use of an Adaption of the GSS' (2002) 15 Journal of Applied Research in Intellectual Disabilities 8.

48 I C H Clare and G H Gudjonsson, 'The Vulnerability of Suspects with Intellectual Disabilities during Police Interviews: A Review and Experimental Study of Decision-Making' (1995) 8 Mental Handicap Research 110; G H Gudjonsson and N K Clark, 'Suggestibility in Police Interrogation: A Social Psychological Model' (1996) 1 Social Behaviour 83.

49 Ellison (n 38) 359-60.

50 M Brennan and R E Brennan, Strange Language - Child Victims under Cross-examination (Riverina Murray Institute of Higher Education 1988) 87.

51 Levy (n 45) 227.

52 Bennett and Feldman (n 20) 132.

53 Evans' advocacy manual, for example, encourages advocates to adopt a strategy of 'probing the witnesses recollection on things which are anything but central to the case'. See K Evans, Advocacy in Court: A Beginner's Guide (Blackstone 1995) 161.

54 L L Weinreb, The Denial of Justice (Free Press 1977). 
implicitly taken to be evidence of a witness's untruthfulness. ${ }^{55}$ In this regard, 'witnesses' behaviour and performance in the witness box may be as important as the substance of what they have to say'. ${ }^{56}$ Empirical support for this observation is to be found in an important study conducted at Bristol University into incidents of child abuse wherein one lawyer confessed that 'juries acquit sometimes because they don't like the look of the victim'. ${ }^{57}$ Herein, we again encounter difficulties arising from the adversarial tradition's mainstream construction of victimhood which creates 'a real problem for all complainants whose appearance or demeanour does not engage the jury's sympathies'. ${ }^{58}$

For victims with intellectual disabilities, these credibility hurdles are further compounded by the adversarial model's restrictive evidential protocols which limit both the admission of expert testimony in court and the degree of pre-trial consultation permitted between counsel and prosecution witnesses. According to the strict dictates of legal adversarialism, expert evidence is only admissible in relation to technical matters which fall outside the ordinary knowledge and expertise of the tribunal of fact. ${ }^{59}$ The probable truthfulness of a witness's account is not regarded as such a matter. ${ }^{60}$ As a consequence, jurors are tasked with making value judgements about the credibility of all witnesses - including those with an intellectual disability - without the benefit of any psychological insights to guide them.

\subsubsection{Insistence on unrehearsed testimony as a barrier to inclusion}

In addition, the witness's task of relaying a convincing narrative in court is complicated by the adversarial system's entrenched insistence upon the delivery of unrehearsed testimony in court. As Hoyano explains:

The prevailing view... is that a witness who gives a spontaneous and unconsidered answer to a question out of the blue is more likely to be telling the whole truth, in the most compelling way - in short, to be giving her best evidence - than one who has had an opportunity beforehand to recollect and reflect on the subject matter of the question. ${ }^{61}$

In trial practice, this logic has manifested itself in the shape of a rule prohibiting the coaching of witnesses. ${ }^{62}$ The significant anxiety which this prohibition causes for vulnerable witnesses hardly needs explaining. Indeed, in the inquest which followed the death of Frances Andrade in England, ${ }^{63}$ it emerged that she had had significant misgivings about the paucity of pre-trial support which she received in contrast to the

55 Wellborn (n 31).

56 M Burton, R Evans and A Sanders, 'Vulnerable and Intimidated Witnesses and the Adversarial Process in England and Wales' (2007) 11 International Journal of Evidence and Proof 1, 16.

57 G Davis, L Hoyano, C Keenan, L Maitland and R Morgan, An Assessment of the Admissibility and Sufficiency of Evidence in Child Abuse Prosecutions (Home Office 1999) 35.

58 Birch (n 22) 233.

59 Flynn v Bus Atha Cliath [2012] IEHC 398; R v Turner [1975] QB 834; and People (DPP) v Keogh [2009] IECCA 93.

60 See R $v$ Pinfold and MacKenny [2003] EWCA Crim 364; People (DPP) $v$ Kehoe [1992] ILRM 481.

61 L Hoyano, 'Reforming the Adversarial Trial for Vulnerable Witnesses and Defendants' (2015) Criminal Law Review 107, 122.

62 Per the dicta of Judge LJ in R $v$ Momodou [2005] 2 All ER 571 as cited with approval in Ireland in G O'R $v$ DPP [2011] IEHC 368 [20] (Charleton J).

63 Frances Andrade died of an overdose in 2013, a week after giving evidence at the trial of Michael Brewer for her alleged rape. Frances Andrade was visibly distressed at the gruelling nature of cross-examination and told the court that she felt as though she had been 'raped all over again' following her cross-examination. See A Hill, 'DPP Proposes New Guidelines to Help Victims and Witnesses in Court' The Guardian (London, 19 January 2015). 
significant level of legal assistance which the accused received from his own counsel. ${ }^{64}$ In the moral outrage which followed Ms Andrade's death, even the director of the Crown Prosecution Service in England and Wales, Alison Saunders, was forthcoming in acknowledging the difficulties that this traditional prohibition on pre-trial communication poses for vulnerable victims of crime:

Asking someone to come to court without any idea of what they face in the witness box does not seem fair to me... To stand up in a formal setting and to be asked sometimes difficult and personal questions in front of a court full of strangers is a very big ask. In coming to court to give evidence, victims and witnesses are performing an important public service and I think we can assist them better. ${ }^{65}$

\subsubsection{Trial in public as a barrier to inclusion}

It is also considered essential that adversarial criminal proceedings should take place in a public forum; the underlying assumption being that a witness is less likely to lie in the presence of an audience. However, again here we find little psychological evidence to support this assumption. ${ }^{66}$ The opposite, if anything, is true. Indeed, there are numerous psychological studies attesting to the corruptible effect which stress can have on memory. ${ }^{67}$ From McLeod's research in England and Wales, it would seem that there are few climates less conducive to accurate recall than the hostile arena of the adversarial courtroom. As one respondent in that study explained:

We went into the courtroom and it was bigger and a bit more full than I was expecting. I don't really like busy places. I started to get a headache and I felt all stressed and shaky. I got asked a question and told I had to explain things in my own words. I had to stop for a minute and calm down. ${ }^{68}$

\section{Attitudinal barriers to best evidence}

Two recent quantitative research endeavours point to the subtle subsistence amongst Ireland's criminal justice agencies of a presumptively dismissive attitude towards the competency and credibility of victims of crime with intellectual disabilities. In the first of these studies, McCormack et al noted that, out of 118 confirmed episodes of abuse against persons with intellectual disabilities, only two incidents were prosecuted and only one of those prosecutions resulted in a formal criminal conviction. ${ }^{69}$ In a separate study, meanwhile, Hamilton found that out of 17 cases involving an intellectually disabled crime victim which were classified as rape by the Director of Public Prosecutions (DPP) Prosecution Policy Unit between 2005 and 2007, only four were eventually prosecuted,

64 See 'Frances Andrade Inquest: I thought I was on Trial, Tragic Chetham's Sex Abuse Case Violinist Told Husband' Manchester Evening News (Manchester, 7 July 2014). See also Hoyano (n 61).

65 Hill (n 63). D Barrett, 'Rape Victims Will be Warned of Defence Lawyers' Tactics under New Guidelines' The Telegraph (London, 19 January 2015).

66 See K H Marquis, 'Testamentary Validity as a Function of Form, Atmosphere and Item Difficulty' (1972) 2 Journal of Applied Psychology 167.

67 Gudjonsson and Henry (n 6) 249. See also J C Bringham, A Maass, D Martinez and G Wittenberger, 'The Effect of Arousal on Facial Recognition' (1983) 4 Basic and Applied Social Psychology 279.

68 McLeod et al (n 43) 7.

69 B McCormack, D Kavanagh, S Caffrey and A Power, 'Investigating Sexual Abuse: Findings of a 15-Year Longitudinal Study' (2005) 18 Journal of Applied Research in Intellectual Disabilities 217, 221; C Williams, Invisible Victims: Crime and Abuse against People with Learning Disabilities (Jessica Kingsley 1995) 221. 
whilst another one case was withdrawn. ${ }^{70}$ These figures speak of a legal community that is indoctrinated in a narrow, mainstream construction of victimhood; a community which, on the whole, is sceptical about the testimonial reliability and behavioural credibility of witnesses with intellectual disabilities.

One possible explanation for this cultural scepticism is the paucity of disability awareness training which exists within Irish criminal justice institutions. It is notable, for instance, that at the time of writing, none of the principle stakeholders involved in Ireland's adversarial trial - including the Office of the DPP, the Courts Service, the Law Society, the Bar Council of Ireland and the Judicial Studies Committee - recognise any mandatory disability awareness training programmes for their members. ${ }^{71}$ This absence of legal education precipitates a lack of professional awareness amongst criminal justice agencies which, in turn, fortifies a political climate of neglect for the testimonial needs and concerns of victims of crime with intellectual disabilities.

The end result is that crime victims with intellectual disabilities are bereft of a structured support framework at trial. Neither the DPP nor the Court Service give any express undertaking within the terms of the Victims' Charter - or indeed within any other policy instrument -- to facilitate people with disability as victims of crime. Indeed, within the entire corpus of pro-victim policy literature that has been published to date by Irish criminal justice agencies there is only one single policy protocol dealing specifically with the testimonial concerns of a person with a disability. The provision in question is a brief two-page section entitled 'Guidance on Appropriate Treatment of Persons with Disabilities' in the Committee for Judicial Studies' non-binding guidance note for members of the Irish judiciary which is entitled The Equal Treatment of Persons in Court: Guidance for the Judiciary.

Beyond the obvious instrumental concern that incidents of victimisation will not be reported by people with intellectual disabilities, this absence of a structured support programme poses the additional risk that the heightened challenges which these victims face in court will go unnoticed by those who marshal the proceedings. For example, in a study of the treatment of vulnerable adults at court in England and Wales, the Ministry of Justice identified:

... several cases ... in which the judiciary and magistrates had not been informed of a court user's mental health condition, learning difficulty or limited mental capacity prior to the hearing, despite the court user having disclosed this or its having been clearly identified by a professional at an earlier stage in the case. ${ }^{72}$

Ineffective communication of this nature not only risks depriving eligible witnesses of important testimonial supports at trial, but the uncertainty which it creates for witnesses can greatly compound the courtroom ordeal which faces them. As Burton et al have written in the context of the experience of vulnerable witnesses in England and Wales: 'The practice of delaying applications until the day of trial means that witnesses may have little reassurance in the run up to trial about whether they will have the benefit of special measures. 73

70 J Hamilton, 'Sexual Offences and Capacity to Consent: A Prosecution Perspective' (Annual Conference of the Law Reform Commission, Dublin, 7 November 2011).

71 The need for greater disability awareness training within Ireland's legal profession was acknowledged as far back as 1996, see Commission on the Status of People with Disabilities, Report of the Commission on the Status of People with Disabilities (Commission on the Status of People With Disabilities 1996) para 15.2.

72 McLeod et al (n 43) 8.

73 M Burton, R Evans and A Sanders, Are Special Measures for Vulnerable and Intimidated Witnesses Working? Evidence from the Criminal Justice Agencies (Home Office 2006) 52. 


\section{Addressing the barriers: a note on special measures}

As many commentators have pointed out, Ireland's criminal justice landscape has undergone a dramatic 'victim revolution' in recent years as national policymakers have endeavoured to reconfigure Ireland's courtroom formalities in order to demonstrate an increased sensitivity for the needs and concerns of crime victims. ${ }^{74}$ The enactment of the Victims' Charter, the recognition of a victim's limited right to separate legal representation and the introduction of Victim Impact Statements at sentencing, are all emblematic of a concerted political and legal effort, not only to foster greater support for crime victims at all stages of proceedings (through service rights). but also to actively accommodate their increased participation in the trial process itself (through procedural rights). ${ }^{75}$ Unsurprisingly, victims of crime with intellectual disabilities have not been immune to the ameliorative effect of this inclusionary trend. In recent years, in particular, we have witnessed the unprecedented unveiling of a series of special accommodations within Ireland's paradigmatic adversarial trial with a view specifically to tempering the hostile excesses of the courtroom contest for vulnerable witnesses. Accordingly, under the legislative bricolage which governs the delivery of evidence in Irish courts, child witnesses and witnesses with an intellectual disability can expect to benefit from at least some of the following measures: (i) a presumption in favour of giving evidence via a live television link; (ii) the removal of wigs and gowns; (iii) the use of intermediaries; (iv) the admission of video-recorded evidence and sworn depositions in court; (v) the use of screens; and (vi) a prohibition on the personal cross-examination of child witnesses and adult complainants by accused persons in trials for sexual offences.

However, while the vast improvements wrought for vulnerable witnesses by the introduction of these special measures cannot be gainsaid, it would be misleading to view the accommodations introduced by the Criminal Evidence Act 1992 and, more recently, by the Criminal Law (Sexual Offences) Act 2017, as a panacea for all of the ills of Ireland's adversarial model of justice. Indeed, there is disconcerting evidence that victims of crime with intellectual disabilities continue to fall through the cracks in Ireland's trial apparatus due to the inadequacy of our existing support framework, the stubborn mainstream attitudes of the Irish legal profession and the overly pathological and disempowering discourse within which this reformative exercise has been rooted.

\subsection{THE LIMITED RANGE AND ACCESSIBILITY OF SUPPORT MEASURES}

At a basic level, Ireland's special measures framework can be criticised for the general paucity of the testimonial protections which it statutorily affords to vulnerable witnesses in court. Unlike our neighbours in England and Wales, Irish law does not, at present, ${ }^{76}$ recognise adult witnesses with intellectual disabilities as having any legal right to the use of screens in court, ${ }^{77}$ nor does it recognise such witnesses as enjoying any legal right to

74 See, for instance, S Kilcommins and M Donnelly, 'Victims of Crime with Disabilities in Ireland: Hidden Casualties in the "Vision of Victim as Everyman" (2014) 20(3) International Review of Victimology 305; R Coen, 'The Rise of the Victim - A Path to Punitiveness?' (2006) 3 Irish Criminal Law Journal 10.

75 M Rogan, 'Victims' Rights, Theory and Practice - Part I' (2006) 24 Irish Law Times 151.

76 It should be noted that s 36 Criminal Law (Sexual Offences) Act 2017 provides for the insertion into the Criminal Evidence Act of a new s 14A which will allow evidence to be given from behind a screen and a new s 14C which will prohibit accused persons from personally cross-examining certain categories of vulnerable witness. At the time of writing, these provisions have not yet commenced.

77 S 23 Youth Justice and Criminal Evidence Act 1999 provides for the use of screens in court in England and Wales where witnesses are vulnerable or intimidated. 
be protected from personal cross-examination by an accused in sexual offence cases. ${ }^{78}$ Moreover, Ireland's legislature has, in more recent times, failed to approximate the statutory pre-trial cross-examination facility which currently exists across the Irish Sea. ${ }^{79}$ Consequently, vulnerable witnesses in Irish criminal justice proceedings continue to face the daunting task of attending court in person for the purpose of undergoing live, crossexamination before members of the jury and the criminal accused. ${ }^{80}$ These statutory shortcomings are acutely regrettable. In a study carried out by Hamlyn et al, for instance, screens were found to be highly regarded amongst vulnerable and intimidated witnesses, and many court users who had not used this facility would have liked to do so. ${ }^{81}$

Pre-trial cross-examination, meanwhile, was introduced on a pilot basis in England and Wales in April 2014. ${ }^{82}$ Staged across three Crown Courts (Liverpool, Leeds and Kingston-upon-Thames), the pilot was launched in order to thelp vulnerable witnesses give their best possible evidence - without subjecting them to the full atmosphere of the courtroom' ${ }^{83}$ Following the successful completion of the scheme last year, Elizabeth Truss launched a joint paper which indicated that pre-trial cross-examination was to be rolled out nationally in England and Wales from 2017. ${ }^{84}$ According to the paper, the pilot results indicate that pre-trial cross-examination 'results in a better experience for witnesses, with the cross-examination taking place in around half the time compared to other cases, and also showed an increase in early guilty pleas by defendants', ${ }^{85}$

Arguably, a further shortcoming of Ireland's current special accommodations regime is its adherence to strict eligibility criteria. ${ }^{86}$ In particular, the restriction of testimonial accommodations under the Criminal Evidence Act 1992 to certain specified offences is profoundly irrational. In Speaking Up for Justice, the Home Office Interdepartmental Working Group in the UK expressly rejected the notion of an 'offence gateway' on the reasoning that 'a witness was either vulnerable or $\mathrm{s} / \mathrm{he}$ was not and ... the offence was relevant to the extent to which it helped to inform the assessment of vulnerability, ${ }^{8}$ Moreover, the failure of Ireland's Criminal Evidence Act 1992 to extend its procedural accommodations on an equal basis to defendants is a further cause for concern. As it stands under Irish law at present, vulnerable defendants have no special protections

78 It should be noted that s 36 of the Criminal Law (Sexual Offences) Act 2017 provides for the insertion of a new section 14C into the Criminal Evidence Act 1992 which will restrict the right of an accused to crossexamine sexual offence complainants. At the time of writing this provision has not commenced. In England and Wales, ss 34-36 of the Youth Justice and Criminal Evidence Act 1999 provide a statutory prohibition on the cross-examination of adult and child complainants by self-represented defendants.

79 The use of pre-trial cross-examination has been statutorily prescribed in England and Wales since 1999 under s 28 Youth Justice and Criminal Evidence Act 1999.

80 See A Cusack, 'Making the Case for Introducing Pre-Trial Cross-Examination' Irish Examiner (Cork, 28 September 2016).

81 B Hamlyn, A Phelps, J Turtle and G Sattar, Are Special Measures Working? Evidence from Surveys of Vulnerable and Intimidated Witnesses (Home Office 2004) ch 6.

82 Ministry of Justice, Process Evaluation of Pre-recorded Cross-examination Pilot (Section 28) (London 2016).

83 Ministry of Justice, Transforming the Criminal Justice System: Strategy and Action Plan - Implementation Update (July 2014) 10 .

84 Ministry of Justice, Transforming our Justice System, by the Lord Chancellor, the Lord Chief Justice and His Senior President of Tribunals (Joint Statement, September 2016).

85 Ibid 8. See further, Cusack (n 80).

86 It should be noted that s 18 Criminal Justice (Victims of Crime) Bill 2016 proposes to extend the category of witnesses eligible for special measures under Part III of the Criminal Evidence Act 1992 to all victims of crime who have 'special protection needs', irrespective of the nature of the offence alleged to have been perpetrated against them. At the time of writing this measure has not been enacted.

87 Home Office, Speaking Up for Justice (Home Office 1998) 3.25. 
equivalent to those afforded to other witnesses. Given that the guilt of the accused has yet to be established at the time of the trial, this inequality of provision would appear to be an explicit infringement of the common law principle of equality of arms. Indeed, the absurdity associated with this lopsided legislative approach has perhaps best been encapsulated by Birch in the following hypothetical scenario:

If A and B are equally disabled, and B's answer to a complaint of sexual assault made by $\mathrm{A}$ is that $\mathrm{A}$ was the aggressor and he the victim, why should $\mathrm{A}$ be the only one to benefit from special measures because it has been decided to prosecute $\mathrm{B} .{ }^{88}$

Ireland's subsisting approach would also appear to be at odds with the stance adopted by the European Court of Human Rights on this issue. In $T v T$ The $U K^{89}$ the court emphasised the need for special provisions to be made available to child defendants in order to allow them to participate effectively in the trial process. More recently, in $\mathrm{R}$ (on the application of C) $v$ Sevenoaks Youth Court, ${ }^{90}$ the Divisional Court held that notwithstanding the absence of any express statutory power, a youth court had an inherent jurisdiction under both the common law and under procedural rules to appoint an intermediary for a defendant who had an intellectual disability in circumstances where such a measure was necessary to ensure he received a fair trial and could participate effectively. More recently, the same court required the Ministry of Justice to reconsider a decision whereby it refused to make available to a vulnerable defendant the services of a registered intermediary. ${ }^{91}$

\subsection{POOR PROFESSIONAL PRACTICE}

The inadequacy of Ireland's statutory special accommodations framework is compounded by a reluctance amongst Irish legal professionals to invoke the limited number of measures which currently exist on our statute book. It is striking, for instance, that, although having existed on our statute book since 1992, the facility for delivering evidence through an intermediary was only used for the first time in this jurisdiction on 12 April 2016.92

As a consequence of this cultural lack of enthusiasm for Ireland's statutory special measures framework, practitioners and members of the judiciary have shown themselves to be unfamiliar with the significant procedural issues involved in granting accommodations under the Criminal Evidence Act 1992. Indeed, the damaging effect which this culture of ignorance can have on the courtroom experience of victims of crime with an intellectual disability was exemplified in D O'D $v$ DP and Judge Patricia Ryan. ${ }^{93}$ In this case, O’Neill $\mathrm{J}$ in the High Court, ostensibly misinterpreted the legislative framework governing the admission of live link testimony with the resulting effect that two complainants with mild intellectual disabilities were faced with the prospect of delivering viva voce evidence against an applicant in the Circuit Court in a trial on sexual offences. In representing, what Kilcommins and Donnelly have termed 'a blindingly narrow emphasis on adversarial legalism - rooted stubbornly in a state-accused way of knowing', this decision is an indictment of Ireland's criminal justice process and speaks of a legal system 'unwilling to adjust its practices to accommodate the different

88 Birch (n 22) 242-3.

89 (1999) ECHR 170.

90 [2010] 1 All ER 735.

$91 \mathrm{R}$ (on the application of OP) $v$ Secretary of State for Justice and Others [2014] EWHC 1944 (Admin).

92 Irish Legal News, 'Irish Courts See First-ever Use of an Intermediary' (13 April 2016) <www.irishlegal.com/ 4031/irish-courts-see-first-ever-use-of-an-intermediary/\#>.

93 [2009] IEHC 559. 
circumstances of some witnesses and the distress and trauma that giving evidence in court may cause them'. ${ }^{94}$

Additionally, at a more primitive level, before a court can even begin to assess the merits of an application for a special accommodation, it must first have the technical wherewithal to provide the requested support. Here, again, we have reason to be concerned. Notwithstanding the fact that the Court Service has undertaken major renovations of many of the court buildings throughout Ireland in recent years, it is nevertheless alarming to find that almost a quarter of a century after the enactment of television link testimony, some courts in this country are still unable to provide this facility due to a lack of resources. ${ }^{95}$ Moreover, even those courthouses which do benefit from the necessary technology have, on occasion, been found inept at putting it into operation. Most recently, for instance, a trial of a mother for cruelty and neglect at Galway Courthouse collapsed when it was discovered that there had been a failure to record footage of a child witness who gave testimony via a live television link. ${ }^{96}$

\subsection{DISEMPOWERING DISCOURSE}

One of the paradoxes that victims of crime with intellectual disabilities face in seeking the benefit from special accommodations set out in the Criminal Evidence Act 1992 is that, in order to be eligible for these measures, they must first subscribe to a pathological discourse which is based entirely upon a medicalised understanding of disability. This prescriptive identification process, Edwards points out, goes 'against everything people with disabilities and the disability movement have fought for; that is the right to autonomy, independence and self-determination'. ${ }^{97}$ Specifically, in order for an adult witness to be eligible for special accommodation in court, he or she must first satisfy the court that they are a 'person with a mental handicap' within the meaning of the Act. ${ }^{98}$ Not only is this phraseology problematic in terms of perpetuating pejorative and outdated language, but it is also grounded in a presumption of incompetence.

Consequently, victims of crime with intellectual disabilities in Ireland face a serious credibility challenge in seeking, on the one hand, to demonstrate their vulnerability for the purpose of being granted a special accommodation in court without, on the other hand, cultivating an ethic of unreliability in the eyes of the jury. One health and social care provider interviewed by Edwards et al summed up this dichotomous challenge in the following terms: 'It's difficult, it's like a seesaw, in one way you're saying they're vulnerable and there's a power imbalance and at the same time you're saying, but we absolutely believe they're able to give evidence and that the evidence is truthful'. ${ }^{99}$ This disempowering effect of Ireland's legislative regime is compounded by the fact that the country's special measures scheme was ostensibly designed to meet the needs of child

94 Kilcommins and Donnelly (n 74) 316.

95 See A Lucey, 'No Kerry Court has Facilities for Minors to Give Video-link Evidence' Irish Times (Dublin, 22 January 2016).

96 A Healy, 'Trial of Mother for Cruelty to Eight Children Collapses' Irish Times (Dublin, 3 December 2015).

97 C Edwards, 'Pathologising the Victim: Law and the Construction of People with Disabilities as Victims of Crime in Ireland' (2014) 29(5) Disability and Society 685, 692.

98 See s 19 Criminal Evidence Act 1992. It is striking that the Criminal Law (Sexual Offences) Act 2017 did not remove this pejorative terminology from the 1992 Act given that elsewhere in the instrument, the term 'protected persons' is used to refer to persons with intellectual disabilities who are incapable of consenting to sex. See s 21 Criminal Law (Sexual Offences) Act 2017. Section 30 of the Criminal Justice (Victims of Crime) Act 2017 is expected to amend s 19 of the Criminal Evidence Act 1992 by replacing the phrase 'mental handicap' with the phrase 'mental disorder'. At the time of writing, this provision has not been commenced.

99 Edwards et al (n 26) 111. 
witnesses, not persons with an intellectual disability. As Benedet and Grant have been at pains to point out, the credibility of a witness with an intellectual disability is severely diminished when he or she is compared to and treated as a child:

When women with mental disabilities are treated like children, their credibility is often correspondingly diminished. They are also subject to a host of incorrect assumptions about the kinds of supports that will facilitate their testimony, by simple analogy to the situation of child witnesses. ${ }^{100}$

\section{Conclusion}

The barriers which victims of crime with intellectual disabilities face in seeking to deliver best evidence in court are formidable. Ireland's adversarial trial, through its subscription to a hostile, exclusively oral, contest morphology, is not only blind to the ontological realities of intellectual disability, but it positively exacerbates them. The requirement that witnesses deliver testimony under oath, that they be subject to cross-examination, that their demeanour be observable to the tribunal of fact, and that their interrogation take place in a public forum, all present significant testimonial challenges to victims of crime with intellectual disabilities. Yet conventional adversarial legal wisdom accepts these evidentiary safeguards unconditionally. Moreover, the strategic incentives of the adversarial contest have cultivated a predatory Irish advocacy culture within which vulnerable witnesses can find themselves exposed to highly invasive credibility attacks in court. Victims, it would seem, to the limited extent that they have been given any formal consideration in Ireland's modern criminal justice process, have been cast as a homogeneous group; defined almost exclusively by the needs of the mainstream victim constituency. Consequently, in a legal system which places inordinate emphasis on consistency of account and credibility of recount, victims of crime with intellectual disabilities are doubly victimised, first as victims of crime and secondly as victims of the legal process and profession.

While a number of special accommodations have been introduced into the Irish trial framework in recent years to support vulnerable witnesses, these concessions have, for the most part, been rooted epistemically in an adversarial value system and have done little to dilute the entrenched hostility of the trial. To quote Birch, the approach of our legislature has been to 'hammer the square peg of the vulnerable witness into the round hole of the adversarial system'.101 Accommodation, however, is not the same as integration. Restricting Ireland's reforms to solutions which fit within the limited confines of our established trial framework arguably represents a missed opportunity to engage in a wider, holistic re-evaluation of the embedded assumptions of Ireland's adversarial criminal process. In 2007, Benedet and Grant declared that 'The greatest impediment to accommodating complainants with mental disabilities lies in our assumptions about what is necessary to ensure a fair trial for an accused. ${ }^{102}$ Indeed, for too long, the inculpatory design of Ireland's adversarial trial has eclipsed efforts to secure the best evidence of vulnerable witnesses. ${ }^{103}$ With Ireland's approaching (and overdue) transposition of the Victims' Directive, policymakers now have a unique opportunity to re-examine the formalities of Ireland's criminal trial in light of the experience of victims of crime with

$100 \mathrm{~J}$ Benedet and I Grant, 'Hearing the Sexual Assault Complaints of Women with Mental Disabilities: Evidentiary and Procedural Issues’ (2007) 52 McGill Law Journal 515, 523-4.

101 Birch (n 22) 223.

102 Benedet and Grant (n 100) 547.

103 See generally, A Cusack, 'From Exculpatory to Inculpatory Justice: A History of Due Process in the Adversarial Trial' (2015) 2 Law, Crime and History 1. 
intellectual disabilities. ${ }^{104}$ Although this re-evaluative exercise may well entail challenging some fundamental truths about Ireland's adversarial tradition, this should not deter Irish policymakers in their inclusionary crusade. After all, there is a strong public interest in empowering victims of crime with intellectual disabilities to give their best evidence in court, not only in the moral sense of ensuring that the legitimate expectations of all court users are equally met within our criminal justice process, but also in the instrumental sense of making sure that those who prey on some of the most vulnerable members of our society are brought to justice.

104 Directive 2012/29/EU of the European Parliament and of the Council of 25 October 2012 establishing minimum standards on the rights, support and protection of victims of crime, and replacing Council Framework Decision 2001/220/JHA 2001/220/JHA [2012] OJL 315. 
